\section{EMBRYRIDDLE \\ Aeronautical University}

SCHOLARLY COMMONS

\section{International Journal of Aviation,} Aeronautics, and Aerospace

\title{
Airport Policing in Pakistan: Structure, Training, and Issue
}

Muhammad Israr

university of peshawar, israr_icp@yahoo.com

Muhammad Abrar

University of Peshawar, abrargeography@gmail.com

Follow this and additional works at: https://commons.erau.edu/ijaaa

Part of the International and Area Studies Commons, and the Organization Development Commons

\section{Scholarly Commons Citation}

Israr, M., \& Abrar, M. (2019). Airport Policing in Pakistan: Structure, Training, and Issue. International Journal of Aviation, Aeronautics, and Aerospace, 6(4). https://doi.org/10.15394/ijaaa.2019.1368

This Special Purpose Document is brought to you for free and open access by the Journals at Scholarly Commons. It has been accepted for inclusion in International Journal of Aviation, Aeronautics, and Aerospace by an authorized administrator of Scholarly Commons. For more information, please contact commons@erau.edu. 


\section{Airport Policing in Pakistan: Structure, Training, and Issue}

\section{Cover Page Footnote}

i definitely, acknowledge the help of my brother Muhammad Abrar in structuring this article with me. 


\section{Introduction}

The aviation industry is the fastest source of transportation and plays an important role in the economy of a country. The protection and safety of this industry, airports, passengers, and aircraft is the responsibility of every state. Airport Security Force (ASF) has been assigned the task of airport security in Pakistan. ASF is the major player in airport security in Pakistan; this research paper thoroughly describes the formation, organisation, preparedness, and role of ASF in the airports' security. This paper also describes how and why ASF was created in Pakistan. Moreover, important incidents that took place in international aviation since the $1950 \mathrm{~s}$ also contributed to the formation of the ASF. Initially, ASF consisted of 2800 members and officers. Different types of trainings are delivered to the ASF staff to meet the minimum criteria of security at the airports. However, to meet the international challenges of terrorism, more training is needed to equip the airport security in Pakistan with latest training strategies and new machinery.

\section{Literature Review}

Ansari (2014) discussed that the Karachi Airport attack was the first terror initiative by the Taliban against the aviation industry and government installations. The attack came after the Taliban issued threat warnings. The terrorists used their intelligence very cleverly by coordinating different aspects of their attacks. They were well equipped, however; they did not establish their notorious designs.

In the Aviation Security Manual by Thomas (2008), the security concerns of airports of the world have been discussed. It highlights the different measures to be taken for enhancing the security inside the airports. It also discusses the provision of latest security equipment's for strengthening the security at the airports. Moreover, the incidents of hijackings at the international level compelled the states to established security at their airports.

Chaliand and Blin (2007) discussed terrorism, the history of terrorism, and particularly the way it is spreading. The authors also differentiated between the old and new forms of terrorism. The effects of terrorism are longlasting and what happens today has its impacts on future. The beginning and the recent layers of terrorism are discussed in detail.

\section{Statement of the Problem}

The aviation security in Pakistan is a challenge for the people, government, and airport authorities. Terrorists are trained and equipped with the latest sophisticated weapons. They have tried numerous times to attack the aviation industry in Pakistan. The safety and security of the passengers and visitors using airports in Pakistan are of prime importance for the government. The lack of new technological machinery at the airports is not only a risk but uses more manpower than needed for more-advances technology. Better training and technological experience are needed for security personnel to effectively combat terrorism. Local training is not sufficient to meet the 
required standards of aviation security as prescribed by the International Civil Aviation Organization (ICAO).

\section{Unlawful Interferences in Aviation Industry}

The aviation industry is an important and fast source of transportation of people and material all over the world. It has an important role in the global economy and since its inception; the aviation industry is also confronted with many types of unlawful interferences, globally, by the terrorist organizations to disrupt its operations. As per the assessment of ICAO, the history of unlawful interferences to jeopardize the safety of civil aviation and air transportation reveals that it faced numerous types of interferences.

These interferences include the unlawful seizure of aircraft in the air, unlawful seizure of aircraft on the ground, hostage taking on board aircraft or an aerodrome, and forcible intrusion on board an aircraft, at an aircraft, or on the premises of an aeronautical facility. Moreover, interference also can be introduction on board an aircraft or at an airport of a weapon or hazardous device or material intended for criminal purposes. The communication of false information such as to jeopardize the safety of an aircraft in flight or on the ground, of passengers, crew, ground personnel or the general public, at an airport or on the premises of a civil aviation facility and the use of aircraft in service to cause damage to the sensitive installations, important buildings, and places is also possible.

However, the main threat of unlawful interference is hijacking, which is defined as the forcible takeover of an aircraft by an individual or a gang by forcing the pilot in command to fly the aircraft to the airport of their choice for fulfilment of certain demands (Green, 2013) or as described in the article-1 of the Hague convention, 16 December 1970 states: any person who on board an aircraft in flight: unlawfully, by force or threat thereof or by any other form of intimidation, seize or exercise control of the aircraft, or attempt to perform any such act, commits an offence (Levitt, 1986).

The first recorded hijacking took place on February 21, 1931, in Arequipa, Peru (Price, 2007). Hijacking in international civil aviation was used an effective weapon, especially in the decades of 1960-70s, which is quite evident from the facts and figures of the incidents of hijackings. Between 1947 and 1958, 23 hijackings were reported, mostly committed by eastern Europeans seeking political asylum. The world's first fatal hijacking took place in July 1947, when three Romanians killed a flight crew member (Rumerman, 2007). The concept of hijacking in its scope and application emerged as a development in the field of criminology.

It was because of the hijacking events in the decades of 1960s and 1970s that led to the formation of the airport security force (ASF) in Pakistan. The rest of the world also reviewed security arrangements of their own and handed over the security of their airports to the trained and efficient agencies for this purpose. In Pakistan, the duty of airport security force, at that time, initially was to be performed by the Federal Security Force (FSF). Although 
the hijacking incidents took place in 1960s and 1970s, hijackings reached their height in the 1970s. The decade of the 70s had many brutal examples of hijacking which compelled various states of the world to review their aviation security.

\section{Establishment of Airports Security Force}

Such a large number of incidents of hijackings, worldwide, shook the faith of air travellers as it was a matter of serious concern for them and for all those having business and other concerns with aviation industry. This situation demanded review of the aviation security for taking effective security measures all over the world. Therefore, International Civil Aviation Organization (ICAO), taking cognizance of the above-mentioned incidents of hijackings, emphasized upon its member states to ensure an effective security system for the safety and security of aviation industry in their respective countries. With a view to achieve this very important aim globally, it was decided by the ICAO that each member state must establish a proper and organized force for ensuring aviation security in their respective countries. Pakistan, being a member country of the United Nations as well as signatory to the ICAO conventions, was bound to fulfil its international obligations. Therefore, the then-government of Pakistan decided to establish an organized force for ensuring the security of aviation industry in Pakistan. For this purpose, an Act was passed by the then National Assembly of Pakistan called ASF Act No. LXXVII of 1975.

The Airports Security Force was established in 1976 under the Airport Security Force Act No. LXXVII of 1975.Initially as the Directorate of the Department of Civil Aviation and was assigned the following responsibilities as quoted in the ASF Act, 1975 are reproduced here:

(a) Ensuring security of all airports, aerodromes, aircrafts and civil aviation Installations within the limits of airports and aerodromes and for safeguarding civil aviation against acts of unlawful interference or threats of such interference;

(b) Ensuring security of all structures, equipment's, material and installations belonging to operators and other Government or nonGovernment organizations within the limits of airports and aerodromes, the option $\mathrm{c}$ and $\mathrm{d}$ are omitted;

(e) Ensuring the proper conduct of persons at airports and aerodromes including control of surface vehicles and drivers within the limits of airports and aerodromes;

(f) Ensuring security of aircraft passengers, baggage cargo and mail within the limits of airports and aerodromes;

(g) General maintenance of law and order within the limits of airports and aerodromes in conjunction with the police and taking cognizance of all offences committed at the airports and aerodromes under any law for the time being in force; and (h) Such other functions as the Federal 
Government may by notification in the official Gazette, require the Force to perform.

In the discharge of their functions the officers and members shall be guided by, an act in accordance with, this Act, and the rules and regulations. (The Gazette of Pakistan, 1975, Part 1)

Initially approximately, $2870 \mathrm{x}$ officials in all ranks were enrolled in the ASF and were imparted necessary basic aviation security training. Thereafter the ASF has taken over charge of airport security from the defunct Federal Security Force (FSF) which was disbanded by the then Marshall Law government of Zia Ul Haq in 1977. The FSF was raised by Zulfiqar Ali Bhutto (Prime Minister 1973-1977) in 1973 for maintaining law and order situation in the country, no doubt that the FSF was a well-organized force. Moreover, the staff and officer recruited in the FSF were physically strong, larger males, at 7 major airports i.e. Karachi (now called Jinnah International Airport JIAP), Lahore (now called Allama Iqbal International Airport AIIAP), Islamabad (now called Benazir Bhutto International Airport BBIA), Peshawar (now called Bacha Khan International Airport BKIA), Quetta, Faisalabad, and Multan airports.

A part of the FSF was the assigned the task of the airport security however, at the raising of special security force for airports (the ASF), the security of airport was handed over by the FSF. Initially ASF was part of the then Department of Civil Aviation, now called Pakistan Civil Aviation Authority. However, in March 1981 a Pakistan International Airline (PIA), aircraft in route Karachi to Peshawar, was hijacked by the AL-Zulfiqar organization. After that incident, the government of Pakistan, sensing the contradictory requirements of security and facilitation, separated the ASF from the then Department of Civil Aviation, and in December 1983, it was placed under the folds of the Ministry of Defence. Later, in the year 2013, ASF was separated from the Ministry of Defence under letter No. 4-8/2013-Min 1 Islamabad the 7th June, 2013 and placed under the folds of Aviation Division, Cabinet Secretariat, Government of Pakistan, specially established for looking after and promoting the aviation industry and its activities in Pakistan. This Division is headed by Federal Secretary (i.e., Secretary Aviation).

A serving Major General from Pakistan Army articulates the command of the ASF from Headquarters (HQ), Airports Security Force, which is located near Jinnah International Airport Karachi. He is assisted by a serving Brigadier from Pakistan Army as Deputy Director General, three Directors and seven Additional Directors at HQs level.

\section{Concept of Security}

The aviation security in Pakistan is based on the concept of visible preclusions and that is why numerous checks, multifaceted security is positioned to forestall and counter all the threats that may endanger the civil aviation industry. A minimum deterrence is required for ensuring the safety and security of people and material relating to the aviation industry. Moreover, 
ASF is cognizant of the importance of security and facilitation being a key link in aviation security system and that why ASF and the government of Pakistan tries to sustain an equilibrium between both these aspects. For ensuring the above-mentioned cause, ASF secures the airports by ensuring the Access Control System, such as

- Tickets, boarding cards passes, and its various categories, stickers, etc.

- $\quad$ Passengers \& Baggage Screening e.g. passengers' identification process, frisking-manual, HHMDs (Hand Held Metal Detectors), WTMDs (Walk Through Metal Detectors), double search and scanning, alarm resolution, x-ray machine scanning, Hold Body Search counter and Hand Body Search Counter, permitted and prohibited items both in hand and hold baggage and absolute contrabands, etc.

- $\quad$ Entry Control of Vehicles to Airside, Security of aircrafts and Air Cargo Security, Security of Catering, Perimeter Security. (DSG, Air defense, ASF, Wall- around the perimeter, Fencing- a minimum of 8 feet height, Ditch is very important between the fencing and apron/ runway, Blocks, Towers, Armed personnel carriers (APCs), Quick Response Force (QRF), Foot Patrolling, Gun-mounted Vehicle patrolling, CCTV surveillance, Double-Gate System, ISS, Drop Arms Barrier, Dragon-Teeth Barriers.

- Car Parks Security- (Layered security approach, Snap checking, checking points, foot and vehicle patrolling, frisking, towers, barriers, Under Vehicle Inspection System (UVIS), Closed Circuit Television (CCTV), speed breaker ASF Police and FIU, Operation vehicular search, one passenger one visitor policy, identification, police support, traffic police, and FC. Intelligence Coverage FIU, MI, AI, NI, ISI, IB, SB, Crisis Management Cell, Close Circuit Television (CCTV) Coverage (NVGs, fixed cameras, dome, moveable, mobile dome cameras. Effective Supervision and Monitoring (normal chain of command, ASF Police, FIU, CCTV, Inspection teams and Security surveys. Foot patrolling, gun mounted Vehicle patrolling, vehicle mounted CCTV surveillance, Integrated Security System (ISS) and online supervision links and Contingency plans for unforeseen contingencies like bomb threat, armed raid crowd control and containment drill. (M. Khan, Personal communication, August 5, 2016)

\begin{abstract}
ASF Formations
As we have already discussed the structure and role of HQ ASF, all the units, small and large, come directly under the administration of HQ ASF, located at Karachi. Moreover, these units are headed by Officers commanding (OCs) and Chief Security Officers respectively (CSOs). OCs and CSOs get instructions from HQ ASF, which gets all the necessary instructions from the Aviation Division Islamabad, which is headed by Aviation Advisor, equal to
\end{abstract}


the status of a federal minister. Furthermore, these units are further divided into subunits from operational and administrative point of view for the smooth functioning of units. There are 9 major airports in Pakistan namely; Jinnah International Airport Karachi, Allama Iqbal International Airport Lahore, Benazir Bhutto International Airport Islamabad, Bacha Khan International Airport Peshawar; Quetta International Airport Quetta, Faisalabad International Airport, Multan International Airport, Sialkot International Airport, and Sukkur International Airport. The total airports in Pakistan are 42; 9 major airports and 33 smaller airports (M. Khan, Personal communication, August 5, 2016).

\section{Manpower Resources}

ASF commenced its duty by looking after 7 major airports with a limited manpower of 2870 person in all ranks. However, with the passage of time, civil aviation operations have increased and the tasks of ASF have been expanded. In such a situation, a considerable increase in threat perceptions has also been observed which demanded compatible security arrangements at airports. To keep abreast with the challenges of the current times, the ASF manpower has been increase and presently has more than 10,000 troops of all ranks at different airports in Pakistan. ASF is a modern force and it equally encourages the participation of females in all ranks. Presently, hundreds of females are working equally with the male at all the airports in Pakistan.

\section{Women in ASF}

Like their male counterparts, female officers and officials are an integral as well as an active part of the Airports Security Force. They perform very important roles in almost all fields within the force and in every aspect of civil aviation security. The female officials regularly receive trainings in various fields such as Anti-Terrorist, Unarmed Combat, Martial Arts, Close Quarter Battle (CQB), and Intelligence courses etc. ASF offers these females equal opportunity for promotion and asignment. In ASF, females are deployed for different tasks and fields like the Air guard for the protection of flight security in the air. They act as instructors in the ASF academy to train other female staffs. Female officials in ASF perform duty as machine operator by checking baggage through X-rays machines and also perform intelligence duties to deliver threat information about any suspect situation or occurrence. The role of female in ASF is equally important as that of male staff. In the present security situation in Pakistan and the province of Khyber Pakhtunkhwa, the strict security checking of female passengers and visitors are critical because terrorists may use the females for suicides and physical attacks on the airport. The female passengers and visitors are searched by the trained ASF female searchers. 


\section{Different Types of Training and Course in ASF}

The Airports Security Force Academy is the only institute of its kind in Pakistan which performs the function of imparting aviation security training to the ASF personnel. It organizes all the basic, advanced, and specialized courses for officers and other ranks of ASF, as well as imparting various skills of security to airport functionaries, employees of government/semigovernment, and private organizations on demand. Selected ASF personnel are also sent abroad to different countries for aviation security training from renowned and recognized institutions of the ICAO. In general courses, the academy imparts the following: Basic Aviation Security Course for all Cadres (New Intakes), Advance Aviation Security Course, Company Commanders Course, and Promotion Courses. In specialized courses, the academy offers Officers Law Course, Anti-Terrorism Course, Advance Screeners Course Safe Passage System, Intelligence Course, and Weapon Instructors Course.

\section{Training to Other Departments/ Organizations}

ASF Academy, for its distinguished position in the field of aviation security, attracts airlines and other organizations (operating at the airports) as well as law enforcement agencies of the country to get their personnel trained from this institution. The following organizations of other airport have allowed the opportunity of training officers and staff from ASF Academy: National Assembly of Pakistan (Security Staff), President House Police, PAF, and Coast Guard for Safe Passage System/Advanced Screening.

\section{Training from Other Institutions}

For ensuring an optimal level of competence, ASF personnel are deputed to different organizations for courses in Pakistan. The purpose of these courses is to equip and adapt them to different techniques of security and administration. In this training from different organizations, their performance enhances in the protection of the aviation industry.

- From Civil Defence Academy, training includes Bomb Disposal Course, Bomb Reconnaissance Course, and Suicide Vehicle Bomber Courses.

- From National Police Academy, training includes Capacity Building Courses/ Workshops.

- From Coast Guard/ANF Academy, the Narcotics Identification Detection course is given.

- Similarly, from the FIA Academy, courses/workshops on Current Security Issues, Intelligence Organizations Training Centres Intelligence Courses are given. In addition, MidCareer, Management and administrative Courses (MCMC) from NIPA are also part of the trainings for ASF personnel. 


\section{Foreign Training}

A number of ASF Officers/Officials are sent to the foreign courses every year. It includes many types of trainings, for example, the Aviation Security Management Course, Aviation Security Supervisor Course, and National AVSEC Program Course (ICAO). ASF did not initially participate in different courses of ICAO, but recently with efforts of Director Operation HQs ASF, 18 officers were sent to Bahrain in December 2017, to attend the ICAO course on aviation security. According to the Director, four groups of the same number will participate in the near future for different courses. This is a good initiative for sharing the security experience at different forum of ICAO. The information and knowledge gained may be shared with the rest of the officials of ASF and other law enforcement agencies, working related to airport for ensuring better security to the aviation industry of Pakistan ( $\mathrm{N}$. Ahsan, Personal communication, August 10, 2017).

ASF is equipped with the weapons for securing the aviation industry. Some of the weapons include: RPGs- Rocket-Propelled Grenades, LMGsLight Machine Guns, AUGs- Army Universal Guns, SMGs- Sub Machine Guns, and Sniper guns. The ASF is equipped with technological weapons to cope with the existing threatening scenario, however, it needs further improvement in the weapons and other accessories because terrorist uses modern technological weapons. Importing reliable arms and ammunition from developed countries may be carried out for the protection of aviation industry. Installing and ensuring availability of equipment for smart and quick communication at all airport in Pakistan is needed, including screening machines, metal detectors, ISS, UVIS, explosive sniffers, online supervision system, and communication systems.

\section{Security Screening System}

The security system at most airports is conducted by manual search and electronic devices search. The combination of these two gives better security to the passengers and visitors that are coming to and going out from this airport. Security inside the boundary wall/premises is the responsibility of the ASF. Airports in Pakistan have been declared as a weapon free zone and most passengers are not allowed to carry a weapon inside the airport, except some passenger are allowed to bring personal weapons, however, the weapons must be turned over to proper authorities and are then returned once they have landed at their final destination. Only few declared dignitaries/VIPs/VVIPs are allowed with weapons, but they are always under close observation by the ASF. With all the available human and material resources, efforts have been made to ensure the security of all the people in the premises of the airport. In addition to weapons and arms, other goods and materials which can pose a threat to the aviation security are also prohibited/ discouraged during flight. The carriage of such goods has been defined clearly in the ICAO security aviation and other related documents. Its quantity and location in the plane have also been clearly stated in the ICAOs documents. 


\section{ASF Achievements in Terms of Security}

Some of the achievements made by the ASF in the history of aviation industry include:

On 24 August 1995, on Pakistan International Airlines Fokker flight no. 673, while flying from Islamabad (now called Benazir Bhutto International Airport) to Faisalabad airport, two saboteurs launched an assault on a passenger, a sitting Member of National Assembly (MNA), with the intention to kill him inside the aircraft. One assassin stabbed a sharp pair of scissors in to the victim 's abdomen and the second one tried to cut his throat by means of a sharp razor. The in-flight ASF Air-guards, sensing the situation and intentions of attackers, quickly responded and opened fire upon them. It was a very critical operation in the history of aviation industry to counter the attackers inside the aircraft in the presence of the passengers on board. However, the ASF Air-guards effectively managed the operation and killed both the assassins. It is pertinent to mention here that both the saboteurs were shot dead in forehead by the ASF Air-guards without causing any loss to the lives of passengers on board the aircraft as well as to the aircraft. Lives of all the on-board passengers included the targeted passenger (MNA) as well as aircraft crew were saved and the aircraft safely landed at its destination i.e. Faisalabad airport. The role of exemplary bravery displayed by the ASF Air guards inside an airborne passenger aircraft was highly appreciated by the passengers on board, general masses, national/international media as well as by the aviation security experts. In recognition of their exemplary performance during the above said operation both the ASF Air-guards were later awarded (Gallantry Awards) by the Government of Pakistan (S. Akhtar, Personal communication, July 06, 2016).

On 20 October 2001, at 12:25 hours, in a similar incident at BBIA Islamabad, the ASF staff observed unknown baggage in verandah. On exploring from the nearby passengers, one claimed it as own. However, at about 12:30 hours, the duty ASF staff once again detected that the same bag was lying unattended and its owner was missing. Therefore, sensing the situation as suspicious, the ASF staff quickly shifted the bag to the bomb disposal ditch specified for this purpose at land side of the airport where it exploded shortly. Again, their alertness saved a large number of human lives and the airport was saved from the disaster (H. Ullah, Personal communication, May 10, 2014).

On 16 January 2002, at about 01:55 hours, a person seated in a Suzuki car started firing on the security staff at the main entrance of AIIA Lahore. Three persons were injured due to the firing of terrorist. ASF staff also opened fire at the terrorist but the terrorist managed to escape the scene. In this specific incident ASF staff again displayed extreme alertness by promptly responding to the attack which resulted in the escape of the terrorists from the airport (M. Jamil, Personal communication, April 12, 2012).

On 6 February 2007, at approximately 2100 hours, a car approached a security check post of the Islamabad international airport. The driver stopped 
the car at the security check and as the ASF staff came close for checking the vehicle and its occupants, the passenger of the front seat of the car started shooting at the security staff, wounding a Sub Inspector. Thereafter, the terrorist tried to flee from the spot and ran towards the General Car Parking area. Sensing the intention of the terrorist, ASF staff on duty followed and also opened fire upon him. At that time, the ASF staff, through walkie talkie sets, locked all the exit and entrance gates of the airport. After sensing the situation, the terrorist hurled a hand grenade which caused damage to cars parked in the area, injuring one ASF and one police personnel. Exchange of fire took place between the terrorist and ASF staff; the terrorist was hit. The terrorist was in possession of another hand grenade which exploded and killed him. ASF officials fulfilled their assigned task of ensuring aviation security professionally and thus prevented a major tragedy at the airport. ASF played a viable and appreciable role in the event which protected the lives of functionaries, passengers, and general masses present at the airport. Later on, in recognition of exemplary performance, the ASF Sub Inspector was awarded (Gallantry Award) by the Government of Pakistan (H. Ullah, Personal communication, May 10, 2014).

The most brutal and dangerous attack in the civil aviation history of Pakistan in the twenty-first century is that of the Jinnah International Airport Karachi attack. This attack not only incurred a lot of financial damage to the national exchequer, but has also put a huge human loss to the aviation security people and general masses.

On June 8, 2014, at about midnight, 10 militants who were dressed in ASF uniform and equipped with arms and automatic weapons (SMGs 7.62), hand grenades, (RPGs) rocket-propelled grenades, and other explosives and flammable substances, attacked the old terminal of Jinnah International airport Karachi. ASF troops are well trained and equipped with the latest arms and ammunition; they have the capability of facing any kind of situation. In the attack that took place on the Bacha Khan International Airport Peshawar, the law enforcement agencies, including the army and police, quickly reacted to the attack and not even a single person was able to get through inside the perimeter of the airport.

There have been a number of situations faced, which were dealt effectively by the ASF. The above scenarios show the ASF is trained well and responds quickly to terrorist threats. To ensure a safe air transportation system, the ASF must continue to train with other agencies, keep abreast of current tactics, and continue to have the latest weaponry and equipment available to them.

\section{Conclusion}

The history of aviation is replete with the terrorist incidents but in the decades of 1950s, 1960s, and 1970s the incident of hijacking happened quite regularly and frequently. For the international community and ICAO, these incidents were of serious nature because the growth of the aviation industry 
affects with such incidents. Due to those incidents, most of the states reviewed their aviation security; Pakistan also established ASF for the security of the airports. ASF is a specialized force for the security of the airports working under the auspices of the aviation division. ASF is imparting regular training to it troops for talking any threat to the aviation industry. Its members and officers are trained in the intelligence and security aspects. Due to better training, the ASF is capable to deal to with incidents on the airports, such as the attacks on BKIA Peshawar or JIAP Karachi. The ASF defends at the cost of their lives. ASF has close liaison with other Law Enforcement Agencies, which are directly or indirectly involve in the security of the airport for example, Pakistan Army, PAF, DSG, BDS, IB, and local police etc. although all the above agencies are cooperating with each other in some areas but they need more coherent approach to fight terrorism. New and sophisticated equipment and latest machinery for the Pakistani airports are the need of the hour. 


\section{References}

Ansari, U. (2014, June 9). Pakistan airport attack could be first of many. Retrieved from http://archive.defensenews.com/article/20140609/ DEFREG04/ 306090018/Analysts-Pakistan-Airport-Attack-CouldFirst-Many

Chaliand, G., \& Blin, A(Eds). (2007). The history of terrorism: From antiquity to al Qaeda. Berkley, CA: University of California Press.

Green, B. (2013). Struggling for self-reliance: Four case studies of Australian regional force projection in the late 1980s and the 1990s. doi: http://doi.org/10.22459/SSR.10.2008

Levitt, G. (1986). Is terrorism worth defining? Ohio NUL Rev., 13, 97.

Price. J (2007). Introduction to aviation security. Module 1:15. American Association of Airport Executives. Retrieved from https://www.aaae.org/ AAAE/ AAAEMemberResponsive/Events/ 2015/12/151204/CCO_Master.aspx

Rumerman, J. (2007). U.S. centennial of flight commission. Retrieved 8/20/2007, from http://www.centennialofflight.gov/essay/ Government_Role/security/POL18.htm

The Gazette of Pakistan. (1975, December 18). Part 1. ASF ACT. Retrieved from http://www.na.gov.pk/uploads/documents/1491973293_536.pdf

Thomas, A. R. (Ed.). (2008). The human element in aviation security. Aviation Security Management [3 volumes], 50. Retrieved from https://epdf.pub/aviation-security-management.html 